\title{
Two Warehouse Inventory Model for Deteriorating Items with Time Dependent Demand under Inflation
}

\author{
Deepa Khurana \\ Department of Mathematics, \\ Krishna Engineering College, Ghaziabad (U.P), India
}

\begin{abstract}
In recent years, various researchers have discussed a two warehouse inventory system. This kind of system was first discussed by Hartely (1976) [10]. Hartely presented a basic twowarehouse model, in which the cost of transporting a unit from rented warehouse (RW) to own warehouse (OW) was not considered. Sarma (1983)[20] developed a deterministic inventory model with infinite replenishment rate and two levels of storage. In that model, he extended Hartely's model by introducing the transportation cost. Murdeshwar and Sathe (1985) [16] extended this model to the case of finite replenishment rate. Dave (1988) [5] further discussed the cases of bulk release pattern for both finite and infinite replenishment rates. He rectified the errors in Murdeshwar and Sathe (1985) [16] and gave a complete solution for the model given by Sarma (1983) [20]. In the above literature, deterioration phenomenon was not taken into account. In this paper, an inventory model is developed for deteriorating items with two- warehouse, permitting shortage under inflation and time-value of money. Holding costs and deterioration costs are different in OW and RW due to different preservation environments. The inventory costs (including holding cost and deterioration cost) in RW are assumed to be higher than those in OW. To reduce the inventory costs, it will be economical for firms to store goods in OW before RW, but clear the stocks in RW before OW. The stock is transferred from the RW to the $\mathrm{OW}$ following a bulk release rule.
\end{abstract}

\section{Keywords}

Warehouse Inventory system, Deterioration, Linear time dependent deterioration, optimal solution of system model,

\section{INTRODUCTION}

Inflation plays a very interesting and significant role: it increases the cost of goods. To safeguard from the rising prices, during the inflation regime, the organization prefers to keep a higher inventory, thereby increasing the aggregate demand. This additional inventory needs additional storage space that is facilitated by a rented warehouse. Ignoring the effects of time value of money and inflation might yield misleading results. The warehouse storage capacity is defined as the amount of storage space needed to accommodate the materials to be stored to meet a desired service level which specifies the degree of storage space availability. Stock items to be delivered exactly when needed are impractical. Therefore, it is important to investigate the influence of warehouse capacity in various inventory policy problems.

The assumption that the goods in inventory always preserve their physical characteristics is not true in general because there are some items which are subject to risks of breakage, evaporation, obsolescence etc. Decay, change or spoilage that prevents the items from being used for its original purpose is usually termed as deterioration. Food items, pharmaceuticals, photographic film, chemicals and radioactive substances, to name only a few items in which appreciable deterioration can take place during the normal storage of the units. The first attempt to obtain optimal replenishment policies for deteriorating items was made by Ghare and Schrader (1963) [6], who derived a revised form of the economic order quantity (EOQ) model assuming exponential decay. Later, assuming the deterioration in both warehouses taken as constant, Sarma (1987) [21] extended his earlier model to the case of infinite replenishment rate with shortages. Pakkala and Achary (1992, 1992) [18] extended the two-warehouse inventory model for deteriorating items with finite replenishment rate and shortages, taking time as discrete and continuous variable, respectively. Pakkala and Achary (1994) [19] presented a two level storage inventory model for deteriorating items with bulk release rule. In these models mentioned above, the demand rate was assumed to be constant. Subsequently, the ideas of time-varying demand and stock-dependent demand were considered by some other authors, such as Goswami and Chaudhuri $(1992,1998)$ [8], [9], Bhunia and Maiti (1994, 1998) [2],[3], Benkherouf (1997) [1], Kar et al. (2001) [14] and others.

In addition, due to high inflation rate, the effects of inflation and time value of money are vital in practical environment, especially in the developing national market. To relax the assumption of no inflationary effects on costs, Buzacott (1975) [4] and Misra (1975) [15] simultaneously developed EOQ models with constant demand and a single inflation rate for all associated costs.

Due to the factors mentioned above, Yang (2004) [24] provided a two-warehouse inventory model for a single item with constant demand and shortages under inflation. Instead of the classical view of accumulating shortages at the end of each replenishment cycle, an alternative model in which each cycle begins with shortages has been proposed here. Zhou and Yang (2005) [27] studied stock-dependent demand without shortage and deterioration with quantity based transportation cost, Wee et al. (2005) [24] considered a two-warehouse model with constant demand and weibull distribution deterioration under inflation. Yang (2006) [26] extended Yang (2004) [25] to incorporate partial backlogging and then compared the two-warehouse models based on the minimum cost approach. Jaggi et al. (2007)[12] presented the optimal inventory replenishment policy for deteriorating items under inflationary conditions using a discounted cash flow (DCF) approach over a finite time horizon. Shortages were allowed and completely backlogged. Hsieh et al. (2008) [11] developed a deterministic inventory model for deteriorating items with two warehouses by minimizing the net present value of the total cost. In that model, they allowed shortages and completely backlogged. Ghosh and Chakrabarty (2009) [7] suggested an order-level inventory model with two levels of storage for deteriorating items. In that study, they have assumed that the rate of deterioration in both warehouses was same and the holding cost was different. The inventory held in RW was transferred to OW in bulk size $(\mathrm{K})$ where, $\mathrm{K}$ was less than the capacity of OW till the stock in RW gets exhausted and there was an associated transportation cost. Shortages were allowed and fully backlogged. 
Recently, Jaggi and Verma (2010) [13], Singh et al. (2012) [22], Singh et al. (2013) [23] developed a two-warehouse inventory model with linear trend in demand under the inflationary conditions. In this paper we propose to derive a twowarehouse inventory model for deteriorating items under the effect of inflation and time value of money, where demand follows a rare pattern of combination of the linear time varying and on-hand inventory level. In one of the warehouse (OW), we have considered time-varying linear deterioration and in the other (RW) we have taken weibull distribution deterioration. The stock is transferred from the RW to the OW following a bulk release rule. The aim here is to find the optimal quantity that should be ordered and the optimum number of cycles in which the quantity from RW should be transferred to $\mathrm{OW}$ to maximize the net profit per unit time.

\section{ASSUMPTIONS AND NOTATIONS}

The mathematical model in this chapter is developed based on the following assumptions:

i. Demand rate is deterministic and is a function of time.

ii. Deterioration rate in owned warehouse (OW) is time dependent.

iii. Deterioration rate of the item in rented warehouse (RW) follows a two parameter Weibull distribution.

iv. There is no replacement or repair of deteriorating items during the period under consideration.

v. Production transactions are followed by instantaneous cash flow.

vi. The OW has a fixed capacity of $\mathrm{W}$ units and the RW has unlimited capacity.

vii. The holding costs in RW are higher than those in OW.

viii. Inventory system is considered single item.

ix. Inflation and time value of money are considered.

x. The transfer of stocks from RW to W follows a Krelease rule.

xi. Lead time is zero and the replenishment rate is infinite.

The following notations are used throughout the study:

D ( $t$ ) Demand rate, where D ( t $)=a+b t+c I(t), a, b$ and $c$ are positive constants where $a>b$.

W Capacity of OW

$\mathrm{R} \quad$ Amount of goods stored in RW

$\mathrm{s} \quad$ Per unit selling price of the item

$\mathrm{r} \quad$ Constant representing the difference between the discount rate and inflation rate.

C Purchasing cost per unit item

$\mathrm{H} \quad$ Holding cost per unit per unit time in OW

F Holding cost per unit per unit time in RW,

$\mathrm{F}>\mathrm{H}$.

A Setup cost per cycle.

$\mathrm{I}_{0}(\mathrm{t}) \quad$ Inventory level at any time $\mathrm{t}$ in OW.

$\mathrm{I}_{\mathrm{r}}(\mathrm{t}) \quad$ Inventory level at any time $\mathrm{t}$ in RW.
$\mathrm{M}(\mathrm{t}) \quad$ Rate of deterioration in OW where $\mathrm{M}(\mathrm{t})=\theta \mathrm{t}, \theta$

is a positive constant where

$0<\theta<<1$.

$\mathrm{f}(\mathrm{t}) \quad$ Two parameter probability density function for the rate of deterioration,

$f(t)=\alpha \beta t^{\beta-1} e^{-\alpha t^{\beta}}$ where $\alpha$ is the scale parameter $(\alpha>$ $0), \beta$ is the shape parameter $(\beta>0)$.

$\mathrm{Z}(\mathrm{t}) \quad$ Weibull instantaneous rate function for the stocked items in $\mathrm{RW}, \mathrm{Z}(\mathrm{t})=\frac{\mathrm{f}(\mathrm{t})}{\mathrm{e}^{-\alpha \mathrm{t}^{\beta}}}=\alpha \beta \mathrm{t}^{\beta-1}$

\section{MODEL FORMULATION SOLUTION}

In the development of the model, we assume that a company purchases $\mathrm{S}(\mathrm{S}>\mathrm{W})$ units out of which $\mathrm{W}$ units are kept in OW and $(\mathrm{S}-\mathrm{W})=\mathrm{R}$ units are kept in RW. Initially, the demands are not using the stocks of OW until the stock level drops to (W-K) units at the end of $\mathrm{T}_{1}$. At this stage, $\mathrm{K}(\mathrm{K} \leq \mathrm{W})$ units are transported from RW to OW. As a result, the stock level of OW again becomes $\mathrm{W}$ and the stocks of $\mathrm{OW}$ are used to meet further demands. This process is continued until the stock in RW is fully exhausted. After the last shipment, only $\mathrm{W}$ units are used to satisfy the demand during the interval $\left[T_{n-1}, T_{n}\right]$ and then the shortages occur and completely backlogged during the interval $\left[\mathrm{T}_{\mathrm{n}}, \overline{\mathrm{T}}\right]$.The graphical representation of the whole process is shown in the figures given below:

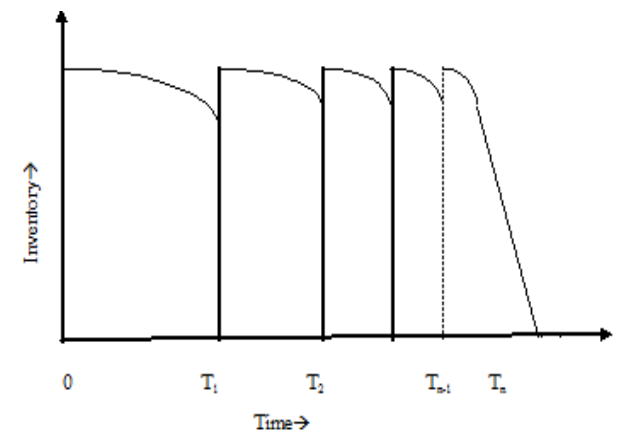

Fig.1 Own Warehouse

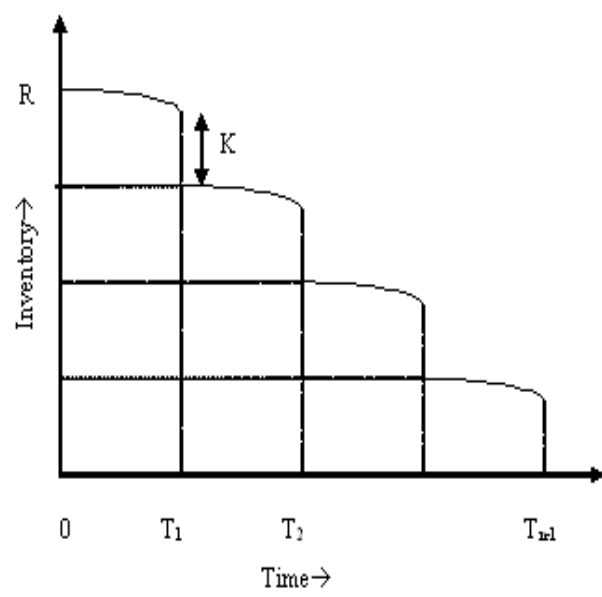

Fig.2 Rented Warehouse 
OW inventory system can be represented by the following differential equation:

$$
\begin{aligned}
& I_{0}^{\prime}(t)=-M(t) I_{0}(t)-D(t), \quad T_{i} \leq t \leq T_{i+1} \\
& I_{0}^{\prime}(t)=-M(t) I_{0}(t)-\left(a+b t+c I_{0}(t)\right), \quad T_{i} \leq t \leq
\end{aligned}
$$$$
\mathrm{T}_{\mathrm{i}+1}
$$$$
\mathrm{I}_{0}^{\prime}(\mathrm{t})=-(\theta \mathrm{t}+\mathrm{c}) \mathrm{I}_{0}(\mathrm{t})-(\mathrm{a}+\mathrm{bt}), \mathrm{T}_{\mathrm{i}} \leq \mathrm{t} \leq \mathrm{T}_{\mathrm{i}+1}
$$

With the boundary condition $\mathrm{I}_{0}\left(\mathrm{~T}_{\mathrm{i}}\right)=\mathrm{W}, \mathrm{i}=0,1,2 . . \mathrm{n}-1$.

Using the boundary conditions, the solution of equation (1) and (2) is given by

$$
\begin{aligned}
\mathrm{I}_{0}(\mathrm{t}) \mathrm{e}^{\left(\mathrm{ct}+\mathrm{t}^{2} / 2\right)}= & a\left(\mathrm{~T}_{\mathrm{i}}-\mathrm{t}\right)+\frac{\mathrm{ac}}{2}\left(\mathrm{~T}_{\mathrm{i}}^{2}-\mathrm{t}^{2}\right)+\frac{\mathrm{b}}{2}\left(\mathrm{~T}_{\mathrm{i}}^{2}-\mathrm{t}^{2}\right)+\frac{\mathrm{a} \theta}{6}\left(\mathrm{~T}_{\mathrm{i}}^{3}-\mathrm{t}^{3}\right)+\frac{\mathrm{bc}}{3}\left(\mathrm{~T}_{\mathrm{i}}^{3}-\mathrm{t}^{3}\right) \\
& +\frac{\mathrm{b} \theta}{8}\left(\mathrm{~T}_{\mathrm{i}}^{4}-\mathrm{t}^{4}\right)+\mathrm{We} \mathrm{e}^{\left(\mathrm{c \textrm {T } _ { \mathrm { i } } + \theta \mathrm { T } _ { \mathrm { i } } ^ { 2 } / 2 )}, \quad \mathrm{T}_{\mathrm{i}} \leq \mathrm{t} \leq \mathrm{T}_{\mathrm{i}+1}, \mathrm{i}=0,\right.}
\end{aligned}
$$

$1,2 \ldots n-2$

Or

$$
\begin{aligned}
I_{0}(t)=[ & a\left(T_{i}-t\right)+\frac{a c}{2}\left(T_{i}^{2}-t^{2}\right)+\frac{b}{2}\left(T_{i}^{2}-t^{2}\right)+\frac{a \theta}{6}\left(T_{i}^{3}-t^{3}\right)+\frac{b c}{3}\left(T_{i}^{3}-t^{3}\right) \\
& \left.+\frac{b \theta}{8}\left(T_{i}^{4}-t^{4}\right)\right] e^{\left(c t+\theta t^{2} / 2\right)}+W e^{\left(c\left(T_{i}-t\right)+\theta\left(T_{i}^{2}-t^{2}\right) / 2\right)},
\end{aligned}
$$

$\mathrm{T}_{\mathrm{i}} \leq \mathrm{t} \leq \mathrm{T}_{\mathrm{i}+1}, \mathrm{i}=0,1,2 \ldots \mathrm{n}-2$

(2)

$$
\begin{gathered}
I_{0}(t) e^{\left(c+\theta t^{2} / 2\right)}=a\left(T_{i}-t\right)+\frac{a c}{2}\left(T_{i}^{2}-t^{2}\right)+\frac{b}{2}\left(T_{i}^{2}-t^{2}\right)+\frac{a \theta}{6}\left(T_{i}^{3}-t^{3}\right)+\frac{b c}{3}\left(T_{i}^{3}-t^{3}\right) \\
+\frac{b \theta}{8}\left(T_{i}^{4}-t^{4}\right), \quad T_{i} \leq t \leq T_{i+1}, i=n-1 \\
\text { Or } I_{0}(t)=\left[a\left(T_{i}-t\right)+\frac{a c}{2}\left(T_{i}^{2}-t^{2}\right)+\frac{b}{2}\left(T_{i}^{2}-t^{2}\right)+\frac{a \theta}{6}\left(T_{i}^{3}-t^{3}\right)+\frac{b c}{3}\left(T_{i}^{3}-t^{3}\right)\right. \\
\left.+\frac{b \theta}{8}\left(T_{i}^{4}-t^{4}\right)\right] e^{-\left(c t+\theta t^{2} / 2\right)}, T_{i} \leq t \leq T_{i+1}, i=n-1
\end{gathered}
$$

The RW inventory system can be represented by the following differential equation:

$I_{r}^{\prime}(t)=-Z(t) I_{r}(t), \quad T_{i} \leq t \leq T_{i+1}$

With the boundary condition $I_{r}(0)=R$ and $I_{r}\left(T_{i+1}\right)=I_{r}\left(T_{i}\right)-K$, for $\mathrm{i}=1,2 \ldots \mathrm{n}-2$

Using the boundary condition, the solution of equation (4) is given by

$I_{r}(t)=\operatorname{Re}^{-\alpha t^{\beta}}, \quad 0 \leq t \leq T_{1}$

$$
\begin{array}{ll}
I_{r}(t)=\left(I_{r}\left(T_{1}\right)-K\right) e^{\alpha\left(T_{2}^{\beta}-t^{\beta}\right)}, & T_{1} \leq t \leq T_{2} \\
I_{r}(t)=\left(I_{r}\left(T_{2}\right)-K\right) e^{\alpha\left(T_{3}^{\beta}-t^{\beta}\right)}, & T_{2} \leq t \leq T_{3}
\end{array}
$$

In general $I_{r}(t)=\left(I_{r}\left(T_{i}\right)-K\right) e^{\alpha\left(T_{i}^{\beta}-t^{\beta}\right)}$

$\mathrm{T}_{\mathrm{i}} \leq \mathrm{t} \leq \mathrm{T}_{\mathrm{i}+1}, \mathrm{i}=1,2 \ldots \mathrm{n}-2$

1. Present worth set-up cost

Order is placed at the beginning of each cycle and hence for every cycle

$\mathrm{SPC}=\mathrm{A}$

2. Present worth item cost

Inventory is bought at the beginning of the cycle and stored separately at the two warehouses. Hence,

$\mathrm{IC}=\mathrm{SC}$

3. Present worth holding cost in OW

Inventory is available during $\mathrm{T}_{\mathrm{i}} \leq \mathrm{t} \leq \mathrm{T}_{\mathrm{i}+1}, \mathrm{i}=0,1$, 2 ...n-1.Hence the holding cost needs to be computed during these time periods.

$$
\mathrm{HC}_{\text {ow }}=\sum_{\mathrm{i}=0}^{\mathrm{n}-1} \mathrm{He}^{-\mathrm{rT} \mathrm{T}_{\mathrm{i}}} \int_{\mathrm{T}_{\mathrm{i}}}^{\mathrm{T}_{\mathrm{i}+1}} \mathrm{I}_{0}(\mathrm{t}) \mathrm{e}^{-\mathrm{rt}} \mathrm{dt}
$$

4. Present worth holding cost in RW

Inventory is available during $\mathrm{T}_{\mathrm{i}} \leq \mathrm{t} \leq \mathrm{T}_{\mathrm{i}+1}, \mathrm{i}=0,1$, $2 . . . \mathrm{n}-2$. Hence the holding cost needs to be completed during these time periods.

$$
\mathrm{HC}_{\mathrm{RW}}=\sum_{\mathrm{i}=0}^{\mathrm{n}-2} \mathrm{Fe}^{-\mathrm{rT} \mathrm{T}_{\mathrm{i}}} \int_{\mathrm{T}_{\mathrm{i}}}^{\mathrm{T}_{\mathrm{i}+1}} \mathrm{I}_{\mathrm{r}}(\mathrm{t}) \mathrm{e}^{-\mathrm{rt}} \mathrm{dt}
$$

5. Present worth Sales Avenue

Since the inventory is available for sale during $\mathrm{T}_{\mathrm{i}} \leq \mathrm{t} \leq$ $\mathrm{T}_{\mathrm{i}+1}, \mathrm{i}=0,1,2 \ldots \mathrm{n}-1$, profit can be gained in this time only. The present worth of profit gained during this time is obtained by the following expression,

$$
\mathrm{SR}=\sum_{\mathrm{i}=0}^{\mathrm{n}-1} \mathrm{~s} \mathrm{e}^{-\mathrm{rT} \mathrm{T}_{\mathrm{i}}} \int_{\mathrm{T}_{\mathrm{i}}}^{\mathrm{T}_{\mathrm{i}+1}} \mathrm{D}(\mathrm{t}) \mathrm{e}^{-\mathrm{rt}} \mathrm{dt}
$$

6. Present worth transportation cost Inventory is transferred from the RW to $\mathrm{OW}$ at $\mathrm{T}_{\mathrm{i}}, \mathrm{i}=0,1,2 \ldots \ldots \ldots(\mathrm{n}-1)$, therefore we have

$$
\mathrm{TRC}=\mathrm{T}_{\mathrm{c}} \sum_{\mathrm{i}=1}^{\mathrm{n}-1} \mathrm{e}^{-\mathrm{r} \mathrm{T}_{\mathrm{i}}}
$$

Present worth total profit:

The present worth net profit is found by deduction various form the sales profit. Using the equations from (7) to (12),

$\mathrm{P}=\mathrm{SR}-\mathrm{SPC}-\mathrm{IC}-\mathrm{HC}_{\mathrm{OW}}-\mathrm{HC}_{\mathrm{RW}}-\mathrm{TRC}$

$$
\begin{gathered}
P=\sum_{i=0}^{n-1} S e^{-\pi T_{i}} \int_{T_{i}}^{T_{i j}} D(t) e^{-t t} d t-A-S C-\sum_{i=0}^{n-1} H e^{-r T_{i}} \int_{T_{i}}^{T_{i+1}} I_{0}(t) e^{-i t} d t-\sum_{i=0}^{n-2} F e^{-r T_{i}} \int_{T_{i}}^{T_{i+1}} I_{r}(t) e^{-i t} d t- \\
-T_{c} \sum_{i=1}^{n-1} e^{-r T_{i}}
\end{gathered}
$$

Here, our aim is to find that quantity, which should be stored in the RW, and the number of times the inventory should be transferred from the RW to the OW so that the net profit might be maximized. This is discussed in the following numerical examples, taking different parameters. 


\section{NUMERICAL ILLUSTRATIONS}

For an inventory system, we considered the following data for solving the equations of the model:

$\theta=0.03, \mathrm{C}=7, \mathrm{H}=1.5, \mathrm{~F}=1.4, \mathrm{~T}_{\mathrm{c}}=60, \mathrm{r}=0.04, \mathrm{~s}=20, \mathrm{~A}=$ 100

With these values we find different solutions of the system for integral values of $n$ i.e. $1,2 \ldots 5$.

Example 1a $=200, \mathrm{~b}=5, \alpha=0.005, \beta=2, \mathrm{~W}=500$

Table 1(a): Time values for different number of cycles

\begin{tabular}{|lllllll|}
\hline $\mathbf{N}$ & $\mathbf{T}_{1}$ & $\mathbf{T}_{\mathbf{2}}$ & $\mathbf{T}_{\mathbf{3}}$ & $\mathbf{T}_{\mathbf{4}}$ & $\mathbf{T}_{\mathbf{5}}$ & $\mathbf{T}_{\mathbf{6}}$ \\
1 & 1.672 & 3.004 & - & - & - & - \\
2 & 1.672 & 3.049 & 4.651 & - & - & - \\
3 & 1.672 & 3.049 & 4.108 & 6.151 & - & - \\
4 & 1.672 & 3.049 & 4.108 & 5.627 & 6.58 & \\
5 & 1.67 & 3.04 & 4.108 & 5.6272 & 7.078 & 8.699 \\
\hline
\end{tabular}

Table 1(b): Optimal values for different number of cycles

\begin{tabular}{|lllccc|}
\hline $\mathbf{N}$ & $\mathbf{R}$ & Cost & Revenue & Net Profit & NP/T \\
1 & 881.2154 & 5432.5744 & 16270 & 2279.233 & 989.79 \\
2 & 1080.0307 & 8540.3737 & 19640 & 4704.879 & \\
3 & 1107.3 & 10436.3723 & 22444 & 5256.3923 & 511.24 \\
4 & 1374.4 & 11275.7224 & 24638 & 6423.1561 & 366.77 \\
5 & 1894.1 & 13224.5237 & 25257 & 7263.5215 & 126.73 \\
\hline
\end{tabular}

Here, we observe that as the number of cycles increases, the net profit decreases, but the net profit per unit time is found to be maximum for $n=1$. Consecutively, it is observed that the net profit as well as the net profit per unit time is found to decrease for increasing number of cycles.

\section{CONCLUSION}

Most of the researchers have till now ignored the effects of deterioration in both the warehouses or have considered a constant rate of deterioration. But we have taken a linear time dependent deterioration rate in OW and weibull distribution type deterioration rate in RW. The model is solved for different system parameters for up to five cycles and the optimal solution is selected from amongst the available solutions. The outcome shows that the net profit per unit time is found to be maximum for the first cycle. The proposed model can be extended in numerous ways. For example, we may extend the demand to a more generalized demand pattern that fluctuates with stock. Also, we could consider the unit purchase cost, the inventory holding cost, and others are also fluctuating with time. Finally, we could generalize the model to allow for quantity discount.

\section{REFERENCES}

[1] Benkherouf, L., (1997), 'A deterministic order level inventory model for deteriorating items with two storage facilities', International Journal of Production Economics, $48(2), 167-175$.
[2] Bhunia, A.K., Maiti, M., (1994), 'A two warehouse inventory model for a linear trend in demand', Opsearch, 31(4), 318-329.

[3] Bhunia, A.K., Maiti, M., (1998), 'A two

a. warehouse inventory model for deteriorating items a linear trend in demand and shortages', Journal of Operational Research Society, 49, 287-292.

[4] Buzacott, J.A., (1975), 'Economic order quantities with inflation', Operational Research Quarterly, 26, 553-558.

[5] Dave, U., (1988), 'On the EOQ models with two levels of storage', Opsearch, 25(3), 190-196.

[6] Ghare, P.M., Schrader, G.H., (1963), 'A model for exponentially decaying inventory system', International Journal of Production Research, 21, 449-460.

[7] Ghosh, S., Chakrabarty, T., (2009), 'An order-level inventory model under two level storage system with time dependent demand', Opsearch, 46(3), 335-344.

[8] Goswami, A., Chaudhari, K.S., (1992), 'An economic order quantity model for items with two levels of storage for a linear trend in demand', Journal of Operational Research Society, 43, 157-167.

[9] Goswami, A., Chaudhuri, K.S., (1998), 'On an inventory model with two levels of storage and stock-dependent demand rate', International Journal of Systems Sciences, $29,249-254$

[10] Hartley, R.V., (1976), 'Operations Research-A Managerial Emphasis', Good Year Publishing Company, California, 315-317.

[11] Hsieh, T.P., Dye, C.Y., Ouyang, L.Y., (2008), 'Determining optimal lot size for a two-warehouse system with deterioration and shortages using net present value', European Journal of Operational Research, 191, 182-192.

[12] Jaggi, C.K., Aggarwal, K.K., Goyal, S.K., (2007), 'Optimal order policy for deteriorating items with inflation induced demand', International Journal of Production Economics, 103 (2), 707-714

[13] Jaggi, C.K., Verma, P., (2010), 'Two-warehouse inventory model for deteriorating items with linear trend in demand and shortages under inflationary conditions', International Journal of Procurement Management, 3(1), 54-71.

[14] Kar, S., Bhunia, A.K., Maiti, M., (2001), 'Deterministic inventory mode with two levels of storage, a linear trend in demand and a fixed time horizon',Computers \& Operations Research, 28, 1315-1331.

[15] Misra, R.B., (1975-a), 'A study of inflationary effects on inventory systems', Logistic Spectrum, 9(3), 260-268.

[16] Murdeshwar, T.M., Sathe, Y.S., (1985), 'Some aspects of lot size model with two levels of storage', Opsearch, 22(4), 255- 262.

[17] Pakkala, T.P.M., Achary, K.K., (1992), 'Discrete time inventory model for deteriorating items with two warehouses', Opsearch, 29(2), 90-103.

[18] Pakkala, T.P.M., Achary, K.K., (1992), 'A deterministic inventory model for deteriorating items with twowarehouses and finite replenishment rate', European Journal of Operational Research, 57, 157- 167. 
[19] Pakkala, T.P.M., Achary, K.K., (1994), 'Two level storage inventory model for deteriorating items with bulk release rule', Operational Research Society of India, Opsearch, 31(3), 215-228.

[20] Sarma, K.V.S., (1983), 'A deterministic inventory model with two levels of storage and an optimum release rule', Opsearch, 20 (3), 175-180.

[21] Sarma, K.V.S., (1987), 'A deterministic order level inventory model for deteriorating items with two storage facilities', European Journal of Operational Research, 29, 70-72.

[22] Singh S.R., Jain S., \& Pareek S. (2012). A warehouse imperfect fuzzified production model with shortages and inflation". Advances in Decision Sciences, Volume 2012, Article ID 638060, 16 pages,doi:10.1155/2012/638060.

[23] Singh, S., Jain, S., \& Pareek, S. (2013). An imperfect quality items with learning and inflation under two limited storage capacity. International Journal of Industrial Engineering Computations, 4(4), 479-490

[24] Wee, H.M., Yu, J.C.P., Law, S.T., (2005), 'Two-warehouse inventory model with partial backordering and weibull distribution deterioration under inflation', Journal of the Chinese Institute of Industrial Engineers, 22(6), 451-462.

[25] Yang, H.L., (2004), 'Two-warehouse inventory models for deteriorating items with shortages under inflation', European Journal of Operational Research, 157, 344-356.

[26] Yang, H.L., (2006), 'Two-warehouse partial backlogging inventory models for deteriorating items under inflation', International Journal of Production Economics, 103(1), 362-370.

[27] Zhou, Y.W., Yang, S.L., (2005), 'A two-warehouse inventory model for items with stock-level-dependent demand rate', International Journal of Production Economics, 95, 215-228. 